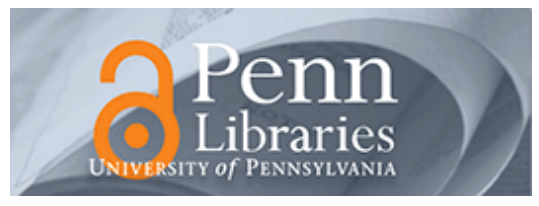

University of Pennsylvania

ScholarlyCommons

Finance Papers

Wharton Faculty Research

4-2015

\title{
The Role of Discount Vouchers in Market with Customer Valuation Uncertainty
}

Fei Gao

University of Pennsylvania

Jian Chen

Follow this and additional works at: https://repository.upenn.edu/fnce_papers

Part of the Finance and Financial Management Commons

\section{Recommended Citation}

Gao, F., \& Chen, J. (2015). The Role of Discount Vouchers in Market with Customer Valuation Uncertainty. Production and Operations Management, 24 (4), 665-679. http://dx.doi.org/10.1111/poms.12296

This paper is posted at ScholarlyCommons. https://repository.upenn.edu/fnce_papers/67

For more information, please contact repository@pobox.upenn.edu. 


\title{
The Role of Discount Vouchers in Market with Customer Valuation Uncertainty
}

\author{
Abstract \\ Online discount voucher market In the discount voucher market, customers usually face two types of \\ valuation uncertainty, namely, preference uncertainty and consumption state uncertainty. Preference \\ uncertainty is related to the customer's lack of relevant experience with the merchant, whereas \\ consumption state uncertainty is related to the advance selling nature of the discount voucher \\ mechanism. By taking a comprehensive perspective (i.e., considering revenue management and \\ promotion effect at the same time), we find (i) no show of voucher buyers may not be a good thing for the \\ merchant, especially for those large or start-up ones; (ii) offering refund may always hurt the merchant's \\ profit and the PayPal model may not be optimal in terms of maximizing social welfare; and (iii) market \\ segmentation is not necessary for the profitability of promotion.

\section{Disciplines} \\ Business | Finance and Financial Management
}




\title{
The Role of Discount Vouchers in Market with Customer Valuation Uncertainty
}

\author{
Fei Gao \\ The Wharton School, University of Pennsylvania, Philadelphia, Pennsylvania 19104, \\ feigao@wharton.upenn.edu \\ Jian Chen \\ Research Center for Contemporary Management, Tsinghua University, Beijing 100084, \\ chenj@sem.tsinghua.edu.cn
}

\begin{abstract}
Online discount voucher market In the discount voucher market, customers usually face two types of valuation uncertainty, namely, preference uncertainty and consumption state uncertainty. Preference uncertainty is related to the customer's lack of relevant experience with the merchant, whereas consumption state uncertainty is related to the advance selling nature of the discount voucher mechanism. By taking a comprehensive perspective (i.e., considering revenue management and promotion effect at the same time), we find (i) no show of voucher buyers may not be a good thing for the merchant, especially for those large or start-up ones; (ii) offering refund may always hurt the merchant's profit and the PayPal model may not be optimal in terms of maximizing social welfare; and (iii) market segmentation is not necessary for the profitability of promotion.

Keywords: customer valuation uncertainty; discount vouchers; revenue management; marketing-operations interface.
\end{abstract}

\section{Introduction}

Third-party promotion platforms have emerged with the development of E-business. The current study discusses the online discount voucher mechanism that has recently captured significant attention in the business world owing to the success of online voucher vendors, such as Groupon and LivingSocial (Roehert, 2010; Surowiecki, 2010). These online voucher vendors sell 
vouchers in specific cities at discounts ranging from $50 \%$ to $90 \%$. These vouchers are typically offered by local businesses, such as restaurants and spas.

Discount vouchers offer buyers a good opportunity to explore and purchase products at huge discounts, with only the requirement of buying in advance. As a result, buyers usually face two uncertainties when they make their decision to purchase:

i. Preference Uncertainty. Voucher buyers are uncertain about their true preference of what they are going to purchase, because the products featured on a voucher vendor's website are relatively new or less known to consumers, and, more importantly, most of the products are experience goods, for which some characteristics cannot be observed until consumption (Nelson, 1970).

ii. Consumption State Uncertainty. This uncertainty is caused by the advance selling nature of the discount voucher mechanism, where consumers have to bear the risk of being in an unfavorable state (e.g., being sick, having a business trip, or even just forgetting he/she has bought the voucher) in the spot period and thus cannot redeem the voucher on time.

What happens when consumers have both valuation uncertainties in their decision process? What are the impacts of each customer valuation uncertainty on the merchant's operational and marketing strategies (e.g., capacity allocation, pricing and refund)? These are the key questions that will be discussed in this paper.

It should be noted that these two uncertainties are different. Preference uncertainty comes from consumers' lack of knowledge about the product attributes. Consequently, consumer valuations are not fixed ex ante and are thus influenced by "external factors," such as consumption experience with the merchant and network effect from other consumers' behavior. On the other hand, consumption state uncertainty, as its name indicates, is related to buyer's consumption state in the spot period. Thus, the merchant or other consumers have no impact on this type of uncertainty. Moreover, not everyone in the market has both uncertainties. Most consumers in the discount voucher channel are not familiar to the product. As a result, they will have to face both uncertainties. Meanwhile, some informed customers who have patronized the merchant 
before may also come to buy the discount voucher. Since they have already known the specific attributes of the product, they need to face only the consumption state uncertainty when they are in the discount voucher channel.

In practice, there are two noteworthy consumer behaviors in the discount voucher market, namely, no-show (i.e., a consumer who has bought a voucher but does not show up before the expiration date) and dilution (i.e., an existing customer buys a voucher at a discount).

Evidence shows that the average redemption rate of Groupon vouchers reaches approximately 80\%. ${ }^{1}$ Besides, Dholakia and Tsabar conducted a real Groupon promotion and discovered a no-show rate of over 30\% (Dholakia and Tsabar, 2011). What is the market's response to the consumer no-show behavior? Three commonly used practices are discussed below. (a) No refund: Some online voucher vendors (e.g., those in China), allow a merchant to not offer refund provided that it is mentioned clearly in the voucher. However, in some countries (e.g., the U.S.), voucher buyers have the right to claim full refund if the voucher expires. In this case, in terms of where voucher buyers ask for refunds, we have the other two refund policies: (b) Refund by the merchant and (c) Refund by the voucher vendor ${ }^{2}$. What is the impact of refund policy on consumers' purchasing behavior? Which type of refund policy is optimal in terms of social welfare? These questions will be answered in this paper.

Based on the survey data gathered from owners of small- and medium-sized US businesses, Dholakia (2012) found that a discount voucher promotion attracts approximately $80 \%$ of new customers on average (i.e., customer dilution rate of approximately 20\%). At first glance, customer dilution does not seem to be a good thing for a merchant because the vouchers are sold to attract new customers rather than existing customers who are willing to pay for the full price. However, the Internet is known as a social networking market, where social influence plays a key role in the consumer's purchasing process (Chen et al., 2011). Specifically, uninformed consumers may be able to reduce their preference uncertainty by learning from the diluted consumers, who know better about the product. In this paper, we will propose a model

\footnotetext{
${ }^{1}$ http://adage.com/article/digital/groupon-preps-national-marketers-gap-promo/145552/.

${ }^{2}$ On its website, Groupon mentions "If merchant refuses to honor any voucher, Groupon will refund the amount paid upon request." See http://www.groupon.com/pages/universal-fine-print
} 
which incorporates the customer dilution behavior, and discuss the impacts of such consumer behavior on a merchant.

In the current study, we focus on the merchants that provide service goods, e.g., restaurants and spas. Typically, they have limited capacity, and their service goods are usually perishable in nature (Edgar, 1997). Thus, an important decision for such a merchant who wants to offer discount vouchers is how to allocate her limited capacity between the spot selling channel and the discount voucher channel. Many anecdotal evidence (e.g., Mcdonald (2012); Cooper (2011)) show that many merchants fail to make money from a Groupon promotion campaign because they lack capacity control (i.e., they sell more than what they can serve). In response to the complaint of the owner of Posies Cafe in Portland, Jessie Burke, who called Groupon "the single worst decision I have ever made as a business owner," the CEO of Groupon, Andrew Mason, said in his official $b \log ^{3}$ :

"[I]t has always been Groupon policy to allow merchants to cap deals. If a merchant sells too many Groupons, they'll have a bad experience, the customer will have a bad experience, and therefore, Groupon loses. In fact, we have the opposite problem more often - where merchants protest a cap we recommend, convinced they can handle more customers than we think they can."

Based on this statement, we can see that (i) selling too many vouchers harms a merchant, and (ii) merchants still have not realized the value of capping the deal (i.e., doing capacity allocation). Thus, analysis on the capacity allocation problem is significantly important.

Traditional revenue management also deals with the capacity rationing problem. However, we will tackle such issue from both the marketing and the operations perspectives. On the one hand, most merchants on Groupon or LivingSocial use the website to run promotions (i.e., marketing effect); On the other hand, they have to match demand with limited supply (i.e., operations effect). In most previous studies on revenue management, the decision-maker is often assumed to be myopic in the sense that she only cares about the immediate profit. This

\footnotetext{
${ }^{3}$ https://blog.groupon.com/cities/too-much-of-a-good-thing/
} 
assumption may not hold when customer repurchasing behavior plays an important role in the daily operation. According to Dholakia's survey (Dholakia, 2010), the percentages of voucher buyers repurchasing a second time are $31 \%$ and $13 \%$ for profitable and unprofitable Groupon promotions, respectively. Thus, the potential future effect should be incorporated into the revenue management model given the merchant's promotion effort.

The remainder of this paper is organized as follows. Section 2 presents the related literature. In the next three sections, we consider three increasingly general versions of the model. We introduce our basic model in Section 3. In Section 4, we extend the model by considering different refund and revenue sharing policies between the merchant and the voucher vendor. In Section 5, we further extend the model by incorporating customer dilution behavior. Finally, in Section 6, we provide conclusions and directions for future research. All proofs are presented in Online Appendix ??.

\section{Literature Review}

Although the recent proliferation of online discount voucher services has garnered substantial press (e.g., Roehert (2010); Surowiecki (2010)), limited studies on this issue have been conducted in the academic literature. Through a survey of the businesses that offered Groupon promotions, Dholakia (2010, 2011) develops and empirically tests a conceptual framework specifying the determinants of a profitable Groupon promotion. Different from Dholakia's survey approach, we will analyze the impacts of the online discount voucher mechanism on merchant's expected profit from a theoretical perspective. Edelman et al. (2010) investigate the profitability of discount vouchers by using the framework of Bils (1989). They examine two mechanisms by which a discount voucher service can benefit affiliated merchants: price discrimination and advertising. They find that offering discount vouchers is more profitable for merchants who are relatively unknown or have low marginal costs. However, unlike the marketing viewpoint of Edelman et al. (2010), we will deal with such issue from both marketing and operations perspectives. In our model, the merchant not only runs the promotion but also manages to utilize her limited capacity. Moreover, we also consider customer no-show and dilution behaviors, which are not 
included in Edelman et al. (2010). In addition, in the model of Edelman et al. (2010), the merchant sells the vouchers, whereas in reality, such promotion is usually performed by a thirdparty voucher vendor (e.g., Groupon), which is the setting considered in the current study.

Our paper also adds to the growing literature on the issue of customers' valuation uncertainty. Xie and Shugan (2001) introduce the concept of consumption state uncertainty, i.e., customers are uncertain about their future consumption states and therefore their valuations. This type of valuation uncertainty can be attributed to the use of advance selling, which separates the purchase and the consumption. Su (2009a) studies the role of consumer return policy as an insurance mechanism where consumers are uncertain of their valuations, i.e., they have preference uncertainty. However, we focus on the service goods that cannot be returned. Instead, the merchant uses the discount voucher mechanism to attract uninformed customers to experience the service with the hope that some of them would come back with full-price payment in the future. We also consider refund policies that are similar to the concept of return policies, except for the target group of customers: Refund is for those who fail to redeem the voucher, whereas return policy is for those who have received the product but find it unsatisfactory. In addition, the effects of positive externalities incurred by the informed customers on others' choices are also considered in the current study. In the marketing and operations management area, various analytical models hae been proposed to characterize the customer social interaction behavior, e.g., group buying model (Jing and Xie, 2011; Chen et al., 2002, 2007), herding model in the queueing theory (Veeraraghavan and Debo, 2009), and network effect (Parker and Van Alstyne, 2005). We are also going to discuss the network effect generated by the existence of diluted customers in the discount voucher channel and its impact on the merchant's performance. In contrast to previous papers, we try to discuss such issue in the contexts of revenue management (where customer dilution is usually regarded as a negative factor) and promotion (where customer segmentation is usually regarded as a necessary condition (Shapiro and Varian, 1999)).

The current study is also related to the literature on revenue management that deals with the issues of capacity control and reservations. The earliest work on capacity allocation problem 
is Littlewood (1972). Based on a simple, two-fare setting, Littlewood proposes the famous Littlewood's Rule, which states that discount fare bookings should be accepted as long as their profit value exceeds the expected profit of future full-fare bookings. Cil and Lariviere (2013) study the role of reservations in the context of restaurants. In their setting, walkingin requires weighing the chance of getting a seat against the cost of asking for service. The consumer's strategic behavior determines the distribution of late demand as a function of how many seats are set aside for walk-ins, which is different from Littlewood's setting where the demand distribution is independent of the number of available seats. As a result, although saving some seats for valuable late arrivals is always optimal in Littlewood (1972), Cil and Lariviere (2013) find that it may be optimal to save no seat for walk-ins. Georgiadis and Tang (2010) investigate the effects of two common reservation deposit policies (i.e., the "no deposit"

policy and the "guarantee deposit" policy), on a rational customer's reservation decision and a firm's optimal expected profit. For most of the previous work, the focus is on how to maximize a firm's immediate profit. However, scant attention has been paid to the potential future impact of the capacity allocation decision. We show that, by allocating some capacity to uninformed customers, a merchant can attract new customers to take a trial and convince some of them to return with full-price purchases. Thus, for a forward-looking merchant, ignorance of potential future effects will result in a suboptimal capacity allocation solution.

\section{The Basic Model}

In this paper, we consider a repeat purchase model. This section details the assumptions about the customer, the merchant, and the operational process. Then, the basic model is proposed in Section 3.4. This model is then extended further by considering different refund and revenue sharing policies and customer dilution behavior in Sections 4 and 5, respectively. The main notations used in this paper are presented in Table 1. 


\subsection{Customer Setting}

There are two types of customer (denoted as he), namely, the informed customer (IC) and the uninformed customer (UC). ICs are those who have patronized the merchant before, whereas UCs have never experienced the service provided by the merchant. Following previous studies on advance selling and customer valuation uncertainty (e.g., Li et al., 2011; Su, 2009b; Xie and Shugan, 2001), we assume buyers have two possible valuations for the service, denoted as $V_{H}$ and $V_{L}$ (where $V_{H}>V_{L}$ ), which depend on whether the service fits their individual needs. For an IC, he knows his exact valuation, which may be either $V_{H}$ (i.e., he likes it) or $V_{L}$ (i.e., he dislikes it), because he has experienced the service. Denote the ICs whose valuation is $V_{H}$ as ICHs and other ICs as ICLs. For a UC, he has preference uncertainty because he has not experienced the service, i.e., he is uncertain about his valuation of the service. However, he expects that the service will fit his needs (i.e., valuation is $V_{H}$ ) with the probability of $\alpha_{e}$ and not fit (i.e., valuation is $V_{L}$ ) with the probability of $1-\alpha_{e}$. After experiencing the service himself, the UC will realize his valuation. Denote the UCs who realize their valuation is $V_{H}$ as UCHs. Moreover, given that each voucher buyer needs to buy the voucher before the actual consumption, he also has to face the consumption state uncertainty. Suppose when deciding whether to buy the voucher, each buyer expects that there will be $\gamma_{e}$ probability that he will be in the unfavorable state and therefore unable to redeem the voucher before it expires. Finally, we assume each customer's demand is at most one unit in each period.

\subsection{Merchant Setting}

The merchant (denoted as she) has a fixed capacity $C .{ }^{4}$ She provides the service at full price $P_{0}$, which is assumed to be equal to $V_{H}$. Meanwhile, for providing one unit of service, she incurs a variable cost $s$, which is less than $P_{0}$. She has some old customers (i.e., ICHs), the total number of which (denoted as $N_{H}$ ) is assumed to be larger than $C$. However, the expected amount of ICHs coming in one period is less than $C$. Thus, the merchant wants to use the discount voucher to induce some new customers to better utilize her capacity. Suppose she

\footnotetext{
${ }^{4}$ In this paper, by "capacity", we mean the total capacity during the voucher's period of validity.
} 
Table 1: Notations

\begin{tabular}{ll}
\hline Exogenous Variables \\
\hline Parameters/variables concerning customers \\
\hline$V_{i}$ & Customers' possible valuations, $i=H, L, V_{H}>V_{L}$ \\
$N_{H}$ & Initial total amount of ICHs \\
$N_{D}$ & Total amount of DCs \\
$\xi$ & The probability of a ICH or UCH coming to buy the service in each period \\
$\alpha_{e}$ & The probability that a UC thinks ex ante his valuation will be $V_{H}$ after experiencing \\
& the service \\
$\alpha$ & The probability that a UC turns out to have a valuation of $V_{H}$ after experiencing \\
& the service \\
$\gamma_{e}$ & The probability that a UC expects that he will not be able to redeem the voucher \\
& before it expires \\
$\gamma$ & The probability of a voucher buyer no-show \\
\hline Parameters/variables concerning the merchant \\
\hline$C$ & Merchant's total capacity \\
$P_{0}$ & Full price of the service provided by the merchant \\
$s$ & Merchant's variable cost for providing one unit of service, $s<P_{0}$ \\
$\delta$ & Merchant's discount factor \\
$\tau$ & The portion of the promotion revenue obtained by the merchant \\
\hline Decision Variables \\
\hline$Q$ & The maximum amount of vouchers that could be sold in the discount voucher channel \\
$P_{v}$ & The price of the discount voucher \\
\hline
\end{tabular}

has a large potential market, i.e., the number of UCs is larger than the maximum capacity the merchant can allocate to the voucher channel (i.e., C). According to Barr (2011), Groupon's total number of subscribers has reached 115 million, while the products featured on the website are sold at most several thousand units. Thus, the assumption about the large amount of UCs is reasonable. The merchant needs to decide the voucher price $P_{v}$ and the maximum amount of vouchers that could be sold in the discount voucher channel $Q \in \mathscr{A}=\{0,1,2 \ldots, C\}$ to maximize her expected profit. With regard to the refund policy, in the basic model, we assume that both the merchant and the voucher vendor do not provide refund. We also assume the voucher vendor shares the total sales revenue with the merchant. Different refund and revenue sharing policies will be discussed in Section 4. Finally, there is no customer dilution behavior in the basic model. This assumption will be relaxed in Section 5 . 


\subsection{Operational Process}

Figure 1 shows the timing of events.

Figure 1: The Process.

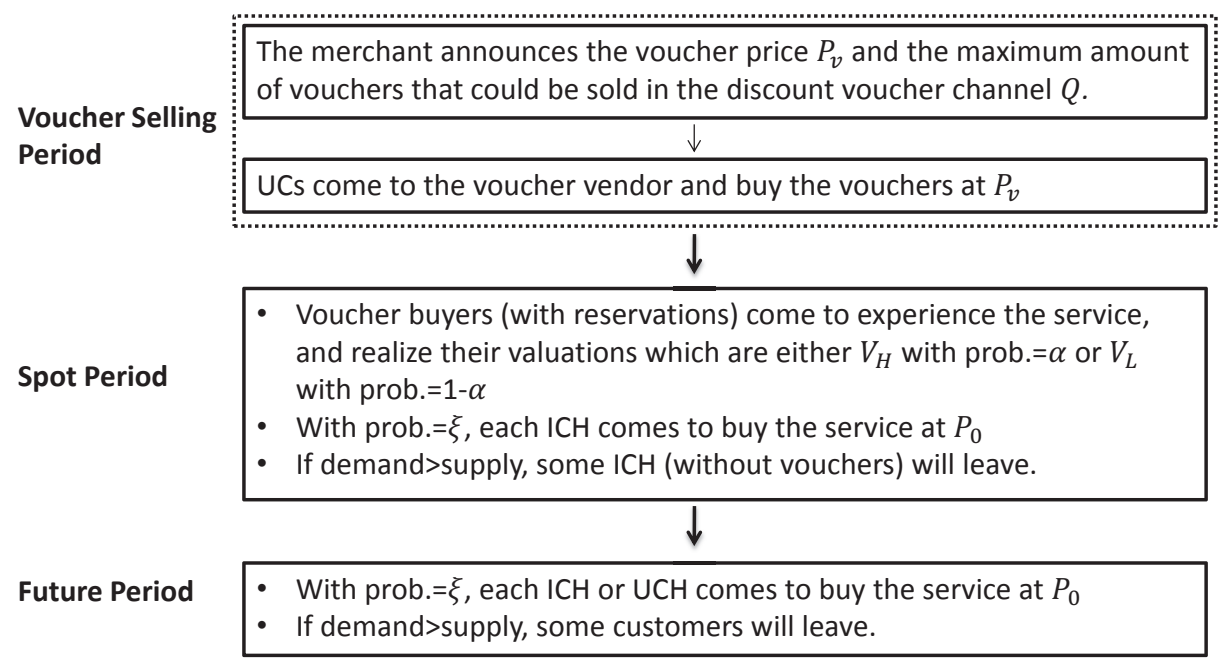

At the beginning of the voucher selling period, given the voucher vendor's commission rate $1-\tau$, the merchant announces the discount voucher price $P_{v}$ and the maximum amount of vouchers that could be sold in the discount voucher channel $Q$. Then, consumers (including only UCs because of the no dilution assumption) visit the voucher vendor's website and decide whether to buy the voucher. If a UC buys the voucher, he has the right to get the service from the merchant in the spot period. A UC will buy the voucher if expected payoff, $\left(1-\gamma_{e}\right)\left[\alpha_{e} V_{H}+\left(1-\alpha_{e}\right) V_{L}\right]-P_{v}$ is nonnegative. Then, clearly, the optimal voucher price is $P_{v}^{*}=\left(1-\gamma_{e}\right)\left[\alpha_{e} V_{H}+\left(1-\alpha_{e}\right) V_{L}\right]$. In this paper, the superscript * denotes the optimal value.

Right before the spot period, voucher buyers should first make reservations ${ }^{5}$. Then, they come to the merchant to enjoy the service. Meanwhile, each ICH may also come to buy the service at price $P_{0}$ with probability $\xi$. Those voucher buyers who fail to make a reservation will be regarded as no-show ${ }^{6}$. Suppose each voucher buyer has $\gamma$ probability of being no-show. Note this no-show

\footnotetext{
${ }^{5}$ Most merchants on Groupon require voucher buyers to make reservations several days ahead of the consumption day. Here, we assume only the voucher buyers make reservations before the consumption. If ICs also make reservations but after voucher buyers do, then our model remains the same. For a more general setting where both types of customers come to the merchant at the same time, our main results still hold (please refer to Online Appendix ??).

${ }^{6}$ Here, for simplicity, we do not specify how customers (including both ICs and UCs) arrive during each
} 
rate could be different from what the customer expects when he buys the voucher (i.e., $\gamma_{e}$ ). After experiencing the service, each show-up voucher buyer may find the service provided by the merchant is good or fits his needs with probability $\alpha$. As a result, he realizes his valuation as $V_{H}$ and is willing to pay full price $P_{0}$ in the future. As for the relationship between $\alpha_{e}$ (UC's expectation of the probability of having a valuation of $V_{H}$ ) and $\alpha$ (UC's realized probability of having a valuation of $V_{H}$ ), many studies (e.g., Bils (1989)) assume $\alpha_{e}=\alpha$, i.e., the UCs have rational expectation. However, our model is not restricted to such constraint. Instead, we allow for any general relationship between $\alpha_{e}$ and $\alpha$. In practice, the merchant can use past transaction data to estimate the value of $\alpha$ and use marketing research techniques, such as questionnaires, to determine the value of $\alpha_{e}$. In this paper, we do not allow for overbooking in the voucher selling period, i.e., the maximum amount of voucher sold is $C$. Moreover, whenever the total number of customers coming is larger than the total capacity $C$, some of those who do not have the voucher may find there is no capacity available and leave this time. ${ }^{7}$

In the future period, each $\mathrm{ICH}$ or $\mathrm{UCH}$ may come to buy the service at $P_{0}$ with the probability of $\xi$. If total number of customers coming is larger than total capacity $C$, then those who find no available capacity will leave.

\subsection{Model and Analysis}

Given the voucher vendor's commission rate of $1-\tau$, the merchant can get $\tau P_{v}^{*} Q$ from the voucher vendor by selling $Q$ vouchers. However, she only needs to pay the variable cost $s$ to $(1-\gamma) Q$ customers expectedly, because she does not need to serve the no-show customers. Thus, her expected profit from the voucher buyers in the voucher selling and spot periods can be expressed as follows:

$$
\Pi_{1 V}=\left(\tau P_{v}^{*}-s\right) Q(1-\gamma)+\tau P_{v}^{*} Q \gamma=\left[\tau P_{v}^{*}-s(1-\gamma)\right] Q
$$

Moreover, she can also sell to the coming ICHs in the spot period and get the expected profit

period. In Online Appendix ??, we show that our main results still hold even if we consider customer arrival process explicitly.

${ }^{7}$ Our main results still hold if voucher buyers and ICs have the same priority in terms of getting the service in the case of excessive demand. Please see Online Appendix ?? for details. 
as follows:

$$
\Pi_{1 I}=\left(P_{0}-s\right) \sum_{q=0}^{Q} b(q ; Q, 1-\gamma)\left[\sum_{n=0}^{C-q} n b\left(n ; N_{H}, \xi\right)+\sum_{n=C-q+1}^{N_{H}}(C-q) b\left(n ; N_{H}, \xi\right)\right],
$$

where operator $b(n ; N, \alpha)=\left(\begin{array}{l}N \\ n\end{array}\right) \alpha^{n}(1-\alpha)^{N-n}$.

Then, in the future period, some UCs (i.e., UCHs) will turn into new ICHs. With a larger customer pool, the merchant will generate the discounted expected profit as follows:

$\Pi_{2}=\delta\left(P_{0}-s\right) \sum_{q=0}^{Q} b(q ; Q, 1-\gamma)\left[\sum_{i=0}^{q} b(i ; q, \alpha)\left(\sum_{n=0}^{C} n b\left(n ; N_{H}+i, \xi\right)+\sum_{n=C+1}^{N_{H}+i} C b\left(n ; N_{H}+i, \xi\right)\right)\right]$

where $\delta>0$ indicates the discount factor reflecting the merchant's attitude towards the future. ${ }^{8}$ A larger $\delta$ implies the merchant cares more about the future, whereas $\delta=0$ means the merchant is myopic. ${ }^{9}$

In summary, the merchant's total expected profit can be written as follows:

$$
\begin{aligned}
\Pi(Q)= & \Pi_{1 V}+\Pi_{1 I}+\Pi_{2} \\
= & \widetilde{P}_{v}^{*} Q+\widetilde{P}_{0} \sum_{q=0}^{Q} b(q ; Q, 1-\gamma)\left[\sum_{n=0}^{C-q} n b\left(n ; N_{H}, \xi\right)+\sum_{n=C-q+1}^{N_{H}}(C-q) b\left(n ; N_{H}, \xi\right)\right. \\
& \left.\quad+\delta \sum_{i=0}^{q} b(i ; q, \alpha)\left(\sum_{n=0}^{C} n b\left(n ; N_{H}+i, \xi\right)+\sum_{n=C+1}^{N_{H}+i} C b\left(n ; N_{H}+i, \xi\right)\right)\right]
\end{aligned}
$$

where $\widetilde{P}_{0} \triangleq P_{0}-s$ and $\widetilde{P}_{v}^{*} \triangleq \tau P_{v}^{*}-s(1-\gamma)$ are defined as the "effective original price" and the "effective voucher price" (i.e., the expected profit the merchant can get from a voucher), respectively. The merchant's optimization problem is to maximize $\Pi$ by choosing the optimal $Q \in \mathscr{A}$.

Note the effective voucher price $\widetilde{P}_{v}^{*}$ can be driven down by two factors, one from the cost of running the promotion $(1-\tau)$ and the other from the cost of serving the customers $(s)$. However, the factor from the customer side (i.e., no-show rate $\gamma$ ) can increase the effective price. This is because the merchant does not have to offer refund to the no-show customer,

\footnotetext{
${ }^{8}$ The merchant does not discount the expected profit from the spot period, because usually the voucher selling period is very short (several days) compared to the spot period (3-6 months).

${ }^{9}$ Here, the merchant could have a discount factor $\delta$ that is greater than 1 . In our model, we only specify two different service periods, i.e., the spot period and the future period. However, any business is a long-term process. As far as the merchant is concerned, the "future" could be the repetition of the future period considered here for many times. Thus, if the merchant's one-period discount factor is $\hat{\delta} \in(0,1)$, then the discount factor $\delta$ defined here can be expressed as $\delta=\hat{\delta}+\hat{\delta}^{2}+\ldots+\hat{\delta}^{\tau}=\frac{\hat{\delta}\left(1-\hat{\delta}^{\tau}\right)}{1-\hat{\delta}}$, where $\tau$ is the merchant's belief about the length of "future" (e.g., the length of time between the current promotion campaign and the next one).
} 
which means she can get the money without providing the service. This seems tempting from the merchant's point of view. Note we have not mentioned the merchant's optimal operational decisions yet. Can the merchant really be so optimistic about customer's no-show behavior? To answer this question, we need to determine the merchant's optimal decision first.

Lemma 1 It is optimal for a merchant to allocate $Q^{*} \in \mathscr{A}$ units of capacity to the discount voucher channel, which satisfies the following:

$$
Q^{*}= \begin{cases}\sup \{Q \in \mathscr{A}: M B(Q) \geq M C(Q)\} & \text { if } M B(1) \geq M C(1) \\ 0 & \text { otherwise, }\end{cases}
$$

where

$$
\begin{gathered}
M B(Q)=\widetilde{P}_{v}^{*}+\widetilde{P}_{0} \delta \alpha \xi(1-\gamma) \sum_{q=0}^{Q-1} \sum_{i=0}^{q} \sum_{n=0}^{C-1} b(q ; Q-1,1-\gamma) b(i ; q, \alpha) b\left(n ; N_{H}+i, \xi\right) \\
M C(Q)=\widetilde{P}_{0}(1-\gamma) \sum_{q=0}^{Q-1} \sum_{n=C-q}^{N_{H}} b(q ; Q-1,1-\gamma) b\left(n ; N_{H}, \xi\right)
\end{gathered}
$$

Similar to the Littlewood's Rule (Littlewood, 1972), Equation (1) represents the tradeoff between giving the marginal capacity to the discount channel (i.e., discount voucher) and protecting the marginal capacity for the full-price class. With regard to giving the marginal capacity to the discount voucher buyer, Equation (1) shows the marginal cost comes from the possibility that an ICH (who is willing to pay full price) leaves because of the limited capacity. On the other hand, the marginal benefit contains two parts. The first part is the direct benefit from selling a voucher; and the other part is the benefit of the potential future value of a UC (i.e., the second term of $M B(Q)$ ), which is what most revenue management articles fail to consider. Littlewood's Rule assumes customer valuations are determined prior to the consumption. Such assumption is reasonable when customers are familiar with the product they are going to purchase beforehand. However, many research articles on economics and marketing (Bils, 1989; Jing and Xie, 2011) have pointed out that customer valuations can change during the purchasing process because of the existence of preference uncertainty. This is especially true in the service sector because most services are experience goods, some characteristics of which cannot be observed prior to consumption (Nelson, 1970). Thus, when the merchant provides the service to her customers, she also provides the new customers with a chance to experience the service. Consequently, some of these customers may like the product and become repeated 
customers. In other words, for a service provider, the discount voucher is not only a revenue management technique to better utilize her limited capacity, but also a marketing tool to promote her service. Actually, running a promotion is one of the first reasons for a merchant to cooperate with online voucher vendors like Groupon (Dholakia, 2010). Therefore, a merchant needs to consider the potential effects of her decision with regard to capacity allocation.

Corollary 1 The merchant will choose to run the promotion if and only if

$$
\left(P_{0}-s\right)(1-\gamma) l(\delta)>s(1-\gamma)-\tau\left(1-\gamma_{e}\right)\left[\alpha_{e} V_{H}+\left(1-\alpha_{e}\right) V_{L}\right]
$$

where $l(\delta)=\delta \alpha \xi \sum_{n=0}^{C-1} b\left(n ; N_{H}, \xi\right)-\sum_{n=C}^{N_{H}} b\left(n ; N_{H}, \xi\right)$

Note function $l(\delta)$ is increasing in $\delta$. Then we can see Inequation (2) always holds when the merchant is extremely forward-looking (i.e., $\left.l(\delta)>\frac{s(1-\gamma)-\tau\left(1-\gamma_{e}\right)\left[\alpha_{e} V_{H}+\left(1-\alpha_{e}\right) V_{L}\right]}{\left(P_{0}-s\right)(1-\gamma)}\right)$. In other words, merchants who care much about the future will always choose to sell the vouchers. Also, we find higher $P_{0}$ and lower $s$ will make Inequation (2) more likely to hold. This result helps to explain why we have seen so many service products, which usually have little variable cost, featured on Groupon. Moreover, Inequation (2) can still be satisfied even when $\tau=0$ (e.g., when $P_{0}$ is large, $s$ is small, and $\left.l(\delta)>\frac{s}{P_{0}-s}\right)$, indicating the merchant may still want to run the promotion even if she will not get any sales revenue from the voucher vendor. This finding helps explain the high commission rate (around 50\%) claimed by Groupon.

A more interesting result comes from the relationship between $Q^{*}$ and $\xi$. According to our numerical example (see Figure 2(a)), the optimal capacity allocation decision $Q^{*}$ is not always decreasing in $\xi$. At first glance, a larger $\xi$, which indicates ICHs are more likely to come in the spot period, will make the merchant less reliant on the discount voucher channel to better utilize her capacity. However, a larger $\xi$ also implies UCHs are more likely to come in the future period, which increases the benefit of acquiring more UCs via the discount voucher channel. This tradeoff can be clearly seen in Figure 2(a). Fewer UCs will actually turn to UCHs when $\alpha$ is smaller (i.e., $\alpha=0.3$ ), making the benefit of acquiring the UCs less significant. Therefore, we see $Q^{*}$ is always decreasing in $\xi$. However, if $\alpha$ becomes larger, which implies more UCs are expected to become repeated customers in the future period, then $Q^{*}$ can be increasing in $\xi$ 
Figure 2: The optimal quantity $Q^{*}$ versus $\xi$ and $\alpha$.
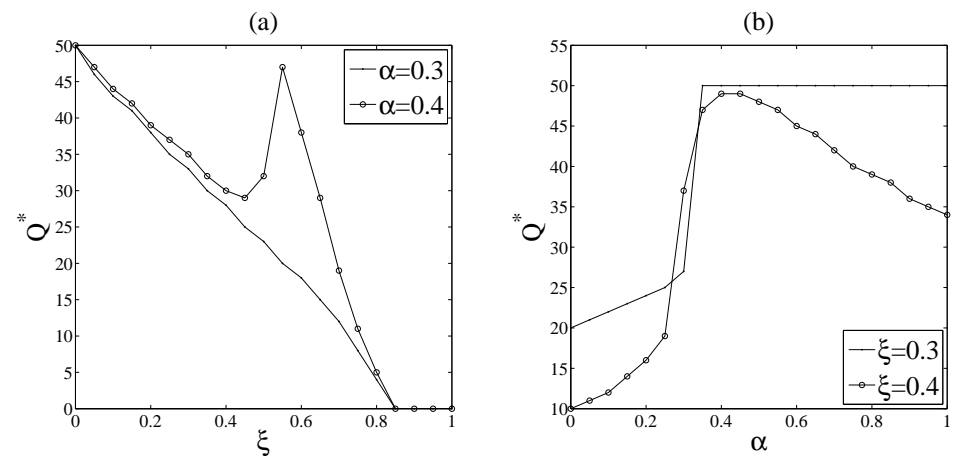

Note: The setting of (a) is $C=50, N_{H}=60, P_{0}=10, \alpha_{e}=\alpha, V_{L}=0, \delta=3, s=0, \gamma=0, \gamma_{e}=0, \tau=1$. The setting of (b) is $C=50, N_{H}=100, P_{0}=10, \alpha_{e}=0.5, V_{L}=0, \delta=5, s=0, \gamma=0, \gamma_{e}=0, \tau=1$.

when $\xi$ is moderate.

Similarly, we also find relationship between $Q^{*}$ and $\alpha$ may not be always monotonic. At first glance, it seems that if voucher buyers are more likely to be with valuation of $V_{H}$, the merchant will be more likely to have a larger customer pool in the future, which should prompt the merchant to attract more voucher buyers through the discount voucher channel. However, according to our numerical example (see Figure 2(b)), $Q^{*}$ may decrease as $\alpha$ increases when $\alpha$ is large. The reason is as follows: Admittedly, if $\alpha$ increases, the merchant will be more likely to have more UCHs in the future. However, if the merchant has already had a relatively lower service level ${ }^{10}$, then the benefit of acquiring UCHs may not be significant. Thus, given the cost of selling the voucher at a discount price, increasing the amount of vouchers that could be sold may not be optimal for the merchant. This tradeoff can be clearly seen in Figure 2(b). It is easy to check when $\xi=0.4$, the merchant's initial service level is lower than the case when $\xi=0.3 .{ }^{11}$ As a result, although $Q^{*}$ is always nondecreasing in $\alpha$ when $\xi=0.3, Q^{*}$ can decrease in $\alpha$ (i.e., when $\alpha>0.4$ ) when $\xi=0.4$.

Let $\Pi_{\gamma}^{*}$ denote the optimal expected profit given the no-show rate $\gamma$.

Proposition 1 If $\delta>\underline{\delta}$, then $\Pi_{\gamma}^{*}$ is decreasing in $\gamma$, where $\underline{\delta}=\frac{1}{\xi \alpha \sum_{i=0}^{C} \sum_{n=0}^{C-1} b(i ; C, \alpha) b\left(n ; N_{H}+i, \xi\right)}$.

\footnotetext{
${ }^{10}$ Service level is defined as the probability of total demand not exceeding total capacity in one period.

${ }^{11}$ Initial service level is $\eta=\sum_{n=0}^{C} b\left(n ; N_{H}, \xi\right)$. Then, since $C>\sum_{n=0}^{N_{H}} n b\left(n ; N_{H}, \xi\right)=\xi N_{H}$, we have $\frac{d \eta}{d \xi}=$ $\sum_{n=0}^{C}\left(\frac{n-\xi N_{H}}{\xi(1-\xi)}\right) b\left(n ; N_{H}, \xi\right)<\sum_{n=0}^{N_{H}}\left(\frac{n-\xi N_{H}}{\xi(1-\xi)}\right) b\left(n ; N_{H}, \xi\right)=0$.
} 
Moreover, $\underline{\delta}$ is decreasing in $C$ and increasing in $N_{H}$.

Proposition 1 indicates customer no-show is not always a good thing for the merchant. At first glance, if a voucher buyer fails to redeem his voucher before the pre-specified expiration date, then the merchant still receives the money paid by the buyer. Moreover, the merchant can give the unit that should have been claimed by the voucher buyer to another ICH in the spot period. However, customer no-show poses a negative effect on the merchant's expected profit as well: If a UC who has bought the voucher fails to redeem his voucher, then he gives up the chance to experience the service provided by the merchant. As a result, he remains uncertain about his preference and is therefore not willing to pay the high full-price $P_{0}$ in the future. Thus, even though the merchant can get money from the no-show customer without providing the service, she may lose a potential high-value customer in the future. For a merchant who really cares about the future (i.e., $\delta$ is large enough), Proposition 1 shows this negative effect is so significant that customer no-show is always a bad thing for the merchant.

Since $\underline{\delta}$ is decreasing in $C$ and increasing in $N_{H}$, customer no-show is more likely to be a negative factor for large (i.e., higher $C$ ) and start-up (i.e., lower $N_{H}$ ) merchants. This is because such merchants really need to build their customer pools to better utilized their capacity. With the development of technology, a merchant can influence the customer no-show rate to some extent. For instance, the merchant can make use of the voucher vendor's email list to send reminders to the subscribers. The merchant can also take advantage of the short message service or social networking websites (e.g., Facebook) to communicate with her customers and ensure they will not forget to redeem their vouchers.

\section{Different Refund and Revenue Sharing Policies}

In Section 3, we assumed no refund is provided to the no-show customers and the voucher vendor shares the whole sales revenue with the merchant. In practice, however, as discussed in the Introduction, at least three different refund policies are considered in the case of customer no-show: 
(R1) zero refund;

(R2) full refund provided by the merchant;

(R3) full refund provided by the voucher vendor.

For R1, as discussed in the previous section, the optimal voucher price is $P_{v 1}^{*}=\left(1-\gamma_{e}\right)\left[\alpha_{e} V_{H}+\right.$ $\left.\left(1-\alpha_{e}\right) V_{L}\right]$. When refund is guaranteed by either the merchant or the voucher vendor, voucher buyers do not have to consider the cost of potential no-show. Thus, they will buy the voucher if $\alpha_{e} V_{H}+\left(1-\alpha_{e}\right) V_{L}-P_{v}$ is nonnegative. Thus, optimal voucher prices under both refund policies R2 and R3, denoted as $P_{v 2}^{*}$ and $P_{v 3}^{*}$, are $\alpha_{e} V_{H}+\left(1-\alpha_{e}\right) V_{L}$.

With regard to the revenue sharing policy, Groupon basically follows two business models (Hickins, 2011):

(S1) In the US, Groupon shares the total revenue from the voucher selling with the merchant.

(S2) In Europe, Groupon pays merchants for vouchers that customers actually redeem and keeps all the revenue from unclaimed vouchers.

Given the capacity allocation decision $Q$ and commission rate $1-\tau$, for different policies RiSj ( $\mathrm{i}=1,2,3, \mathrm{j}=1,2$ ), the merchant's expected profit from the voucher buyers in the spot and future periods $\Pi_{1 V_{i j}}$ and the voucher vendor's expected profit $\pi_{1 V_{i j}}$ are given in Table 2 , where $\widetilde{P}_{i j}^{*}$ are defined as the "effective voucher price" under policy RiSj, $i=1,2,3, j=1,2$.

Table 2: The merchant and voucher vendor's expected profits under different policies

\begin{tabular}{lll}
\hline R1S1: & $\Pi_{1 V_{11}}=\left[\tau P_{v 1}^{*}-s(1-\gamma)\right] Q \triangleq \widetilde{P}_{11}^{*} Q$ & $\pi_{1 V_{11}}=(1-\tau) P_{v 1}^{*} Q$ \\
R1S2: & $\Pi_{1 V_{12}}=\left(\tau P_{v 1}^{*}-s\right)(1-\gamma) Q \triangleq \widetilde{P}_{12}^{*} Q$ & $\pi_{1 V_{12}}=(1-\tau+\tau) P_{v 1}^{*} Q$ \\
R2S1: & $\Pi_{1 V_{21}}=\left[(\tau-\gamma) P_{v 2}^{*}-s(1-\gamma)\right] Q \triangleq \widetilde{P}_{21}^{*} Q$ & $\pi_{1 V_{21}}=(1-\tau) P_{v 2}^{*} Q$ \\
R2S2: & $\Pi_{1 V_{22}}=\left[(\tau(1-\gamma)-\gamma) P_{v 2}^{*}-s(1-\gamma)\right] Q \triangleq \widetilde{P}_{22}^{*} Q$ & $\pi_{1 V_{22}}=(1-\tau+\tau \gamma) P_{v 2}^{*} Q$ \\
R3S1: & $\Pi_{1 V_{31}}=\left[\tau P_{v 3}^{*}-s(1-\gamma)\right] Q \triangleq \widetilde{P}_{31}^{*} Q$ & $\pi_{1 V_{31}}=(1-\tau-\gamma) P_{v 3}^{*} Q$ \\
R3S2: & $\Pi_{1 V_{32}}=\left[\tau(1-\gamma) P_{v 3}^{*}-s(1-\gamma)\right] Q \triangleq \widetilde{P}_{32}^{*} Q$ & $\pi_{1 V_{32}}=(1-\tau)(1-\gamma) P_{v 3}^{*} Q$ \\
\hline
\end{tabular}


The merchant's objective function can be described as the following general form:

$$
\begin{aligned}
\Pi(Q)=\widetilde{P}_{v}^{*} Q+ & \widetilde{P}_{0} \sum_{q=0}^{Q} b(q ; Q, 1-\gamma)\left[\sum_{n=0}^{C-q} n b\left(n ; N_{H}, \xi\right)+\sum_{n=C-q+1}^{N_{H}}(C-q) b\left(n ; N_{H}, \xi\right)\right. \\
& \left.+\delta \sum_{i=0}^{q} b(i ; q, \alpha)\left(\sum_{n=0}^{C} n b\left(n ; N_{H}+i, \xi\right)+\sum_{n=C+1}^{N_{H}+i} C b\left(n ; N_{H}+i, \xi\right)\right)\right]
\end{aligned}
$$

i.e., under policy $\operatorname{RiSj}$, given $Q$, the merchant's profit function $\Pi_{i j}(Q)$ can be expressed in Equation (3) with $\Pi$ and $\widetilde{P}_{v}^{*}$ replaced by $\Pi_{i j}$ and $\widetilde{P}_{i j}^{*}$, respectively. The merchant is to maximize $\Pi_{i j}(Q)$ by choosing a quantity $Q_{i j} \in \mathscr{A}$. Note the voucher vendor's commission rate $1-\tau$ is exogenously given, implying an assumption that the voucher vendor market is competitive. This assumption is reasonable because according to Yipit's data ${ }^{12}$, over 500 hundred discount voucher sites operate in the US. However, the big sites (e.g., Groupon) are still enjoying some extent of market power. Thus, allowing $\tau$ to be a decision variable of the voucher vendor is an interesting future research topic.

\section{Lemma 2}

i. Under revenue sharing policy $S 1$, if $\gamma-\tau \gamma_{e}>(<) 0$, the merchant is worse (better) off by offering refund compared to the no-refund situation, i.e., $\Pi_{21}^{*}<(>) \Pi_{11}^{*}$.

ii. Under revenue sharing policy S2, if $\gamma-\tau \gamma_{e}(1-\gamma)>(<) 0$, the merchant is worse (better) off by offering refund compared to the no-refund situation, i.e., $\Pi_{22}^{*}<(>) \Pi_{12}^{*}$.

From Lemma 2, we can see that the benefit of offering refund depends on both the customer's expected no-show rate $\gamma_{e}$ and the real no-show rate $\gamma$. To voucher buyers, refund serves as an insurance against the consumption state uncertainty (measured by $\gamma_{e}$ ). However, it may not be beneficial to the merchant to provide such insurance. Like any other type of insurance, refund is actually a risk sharing device. By offering refund, the merchant has to take all consumers' risk of being in an unfavorable consumption state (measured by $\gamma$ ). According to Lemma 2, only when voucher buyers expect a much higher no-show rate (i.e., $\gamma_{e}$ ) than the realized one (i.e., $\gamma$ ) can the merchant benefit from offering refund.

\footnotetext{
${ }^{12}$ http://yipit.com/about/services/
} 
Proposition 2 If voucher buyers have rational expectation about their probability of being in an unfavorable consumption state, i.e., $\gamma_{e}=\gamma$, then given a revenue sharing policy and compared to the no-refund situation, the merchant always earns less expected profit by offering refund, i.e., $\Pi_{21}^{*}<\Pi_{11}^{*}$ and $\Pi_{22}^{*}<\Pi_{12}^{*}$.

Xie and Shugan (2001) study a similar advance selling model with consumer consumption state uncertainty, where advance buyers have rational expectation about their probability of being in an unfavorable consumption state. They claim the merchant could sometimes benefit from offering refund in the advance selling context. However, Proposition 2 provides a very different result. The reason is as follows: Xie and Shugan (2001) assume a customer will still consume without refund when he finds his consumption state unfavorable, but will take the refund otherwise. As a result, with the existence of variable cost, offering refund will increase profit by saving cost from not serving customers in an unfavorable state. In the current study, we consider a different setting where the voucher buyer, who finds himself in the unfavorable state (e.g., he may travel in another city and cannot redeem the voucher in time), will not consume regardless of the availability of refund. In this case, offering refund does not have cost saving effect. In reality, however, both types of customer behavior may exist. If a large amount of voucher buyers behave like the one in our setting in the face of unfavorable consumption state, then refund's cost saving effect will be insignificant ${ }^{13}$.

Next, let's discuss the impacts of different refund and revenue sharing policies on social welfare. For simplicity, we focus on the case where voucher buyers have a rational expectation about their no-show rate, i.e., $\gamma_{e}=\gamma$. Define social welfare as the total surplus of the three parties (i.e., consumers, the merchant and the voucher vendor) in the market. Denote $S W_{i j}$ as the social welfare under policy RiSj.

Lemma $3 \Pi_{1 V_{11}}=\Pi_{1 V_{32}}, \pi_{1 V_{11}}=\pi_{1 V_{32}}, \widetilde{P}_{11}^{*}=\widetilde{P}_{32}^{*}$, and $Q_{11}^{*}=Q_{32}^{*}$, i.e., policy R1S1 is effectively equivalent to policy R3S2.

\footnotetext{
${ }^{13}$ Our model can be easily modified to analyze the case considered in Xie and Shugan (2001). For details, please refer to Online Appendix ??.
} 
Under policy R3S2, the voucher vendor takes the role of PayPal by helping secure customer's account and reimbursing them in case of no-show. At first glance, customers would benefit from such policy, which is much "safer" with every transaction compared with the situation under policy R1S1, because they do not have to worry about losing money in the unfavorable consumption state. However, they have to pay for such purchase protection $\left(P_{v 3}^{*}>P_{v 1}^{*}\right)$ : Because the merchant knows that customers do not have to worry about the no-show cost and are willing to pay more for the voucher, she will increase the voucher price to squeeze consumer surplus. Does the merchant benefit from this policy? No. She has to pay for it too, because she cannot get the voucher sales revenue from the no-show customers. Finally, the voucher vendor does not get any more benefits either. Even though the voucher price is higher under policy R3S2 than under policy R1S1, the voucher vendor has to return the money to those no-show customers, which actually means the total quantity sold is lower. As a result, we find the two policies generate the same result for each party in the market. Thus, we have to be more cautious when evaluating the effectiveness of the PayPal model. At least, in the discount voucher market, it may only act as a no-refund policy with a different revenue sharing contract between the merchant and the voucher vendor.

Lemma 4 If $1-\tau-\gamma \geq 0,{ }^{14}$ for a given revenue sharing policy, compared to the situation under no refund policy, the refund offered by the voucher vendor will increase the total social welfare, whereas the refund offered by the merchant will decrease the total social welfare. Mathematically speaking, $S W_{31}>S W_{11}>S W_{21}$ and $S W_{32}>S W_{12}>S W_{22}$.

Lemma 4 can be explained as follows: First, it is easy to check that all customers (including both ICs and UCs) will get zero surplus because they have to pay the price equals to their (expected) valuation. Second, the total effective voucher price (i.e., the merchant's and the voucher vendor's expected profit from one voucher) is the same under all scenarios because the commission fee is simply a profit transfer between the merchant and the voucher vendor. However, it should be noted that the merchant is the one who makes the capacity decisions.

\footnotetext{
${ }^{14}$ Generally, the condition $1-\tau-\gamma \geq 0$ holds in a discount voucher market. For example, Groupon's commission rate is known as 50\% (i.e., $\tau=50 \%$ ) and the no-show rate is usually less than $50 \%$ (Dholakia and Tsabar, 2011).
} 
Thus, if she needs to provide refund herself, then she is willing to sell less vouchers, which in turn, decreases the total sales profit.

Proposition 3 If $1-\tau-\gamma \geq 0$, then $S W_{31}>S W_{i j}, \forall(i, j) \neq(3,1)$.

According to Proposition 3, we find a policy, R3S1, which leads to the largest social welfare among all six policies. Specifically, policy R3S1 is better than the PayPal model (i.e., R3S2) in terms of maximizing social welfare. Thus, the generosity of the voucher vendor, i.e., offering the refund and sharing the total profit with the merchant, will benefit the whole society. Admittedly, the voucher vendor may incur some losses under R3S1. However, given that the social welfare is increasing, the voucher vendor can ask for some lump-sum payment from the merchant. Note the lump-sum payment does not affect the merchant's optimal decision. Therefore, by this way, we can get a Pareto improvement under policy R3S1 where all parties in the market will be (weakly) better off than in the situation under other policies.

In some countries (e.g., the US), the consumer protection regulations stipulate that voucher buyers have the right to ask for a refund. Proposition 3 gives us a suggestion on how to implement such regulations: Instead of asking the voucher "issuer" (i.e., the merchant) to offer the refund, the relevant regulation should demand the voucher "vendor" to offer the refund if it aims to maximize the total social welfare.

\section{Customer Dilution}

In previous sections, the discount voucher market is assumed to have only one type of customer, i.e., UCs . However, in reality, there are also some informed customers buying the vouchers (Dholakia, 2012). In Section 5.1, we further extend our model by incorporating customer

dilution behavior. This model is based on some strong assumptions. In Section 5.2, we will conduct a simulation study to validate our main results. 


\subsection{Simple Model with Dilution.}

Suppose there are some ICs (including ICHs and ICLs) coming to buy the discount voucher in the voucher selling period as well. First, let's look at the case under refund policy R1. The discount voucher serves as an advance selling mechanism in which the diluted ICs have to bear the risk of being in an unfavorable consumption state later (i.e., consumption state uncertainty). Thus, a diluted IC will buy the voucher only if the voucher's price is low enough. Specifically, taking the expected no-show rate $\gamma_{e}$ into consideration, a diluted $\mathrm{ICH}$ will buy the voucher if the voucher price $P_{v 1} \leq\left(1-\gamma_{e}\right) V_{H}$, whereas an ICL will buy the voucher if $P_{v 1} \leq\left(1-\gamma_{e}\right) V_{L}$.

A UC will learn how many people have bought the voucher when making the purchasing decision because most voucher vendors offer real-time sales data on the webpage. When buying the vouchers, UCs have to face the preference uncertainty because they have little private information about the service sold. It is this preference uncertainty that would cause them to be easily influenced by other people's purchasing behaviors. Due to the potential existence of diluted customers, they know others may have some experience with the merchants. As a result, by checking the sales data, a UC may believe the service is more likely to be good if more people have bought the voucher. This type of network effect have been widely shown in literature (e.g., Huang and Chen (2006); Chen et al. (2011)).

Similar to the approach used in some literature (e.g., Farrell and Saloner (1986); Strauss (2002)), we build the following model to capture such kind of network effect. Suppose $n$ people have already bought the voucher. The UC will then update his probability of having a valuation of $V_{H}$ to be $A(n)$, with $A(0)=\alpha_{e}$ and $A^{\prime}(n) \geq 0$. However, the realized probability $\alpha$ will remain unchanged because it is related to customers' experience during the consumption. In addition, this kind of influence is assumed to be limited. After all, UCs still have not "experienced" the service when they buy the voucher. Thus, we assume $A(C)$ to be lower than 1 . Based on the assumptions above, each UC will buy the voucher if expected payoff $\left(1-\gamma_{e}\right)\left[A(n) V_{H}+(1-\right.$ $\left.A(n)) V_{L}\right]-P_{v 1}$ is nonnegative.

We assume the merchant's top priority is to attract some UCs by selling the vouchers, because 
most merchants treat the discount voucher mechanism as a promotion strategy instead of a pure advance selling strategy (Dholakia, 2011). Hence, the merchant will not set the voucher price so high such that only diluted ICHs can afford it. Moreover, because $\left(1-\gamma_{e}\right) V_{L}<$ $\left(1-\gamma_{e}\right)\left[A(n) V_{H}+(1-A(n)) V_{L}\right]$ and the number of UCs in the discount voucher channel is large enough, the merchant will not set the price at $P_{v 1}=\left(1-\gamma_{e}\right) V_{L}$, indicating ICLs will not buy the vouchers even though they may find the promotion on the Internet. Thus, it is sufficient to just consider the ICHs' dilution behavior in our model. Denote the diluted ICHs as the diluted customers (DCs). Here, the total amount of DCs $\left(N_{D} \in[0, C)\right)$ is assumed to be exogenous, i.e., the merchant can expect the amount of diluted customers rationally when making the decision. In practice, $N_{D}$ should be a random variable. However, since we want to focus on the impact of the existence of customers' dilution behavior on the merchant's optimal decision and expected profit, we ignore the randomness of $N_{D}$ in this section. In Section 5.2, a simulation study is conducted to show our main results in this section still hold even when $N_{D}$ is random.

In Section 5.1, we only consider a static setting, which will be relaxed to allow for stochastic customer arrivals in the simulation study later. Specifically, we assume all customers (including UCs and DCs) are already in the discount channel when the promotion begins. Moreover, DCs will act before UCs do because DCs are familiar with the service and will spend less time thinking or making the decision (Shugan, 1980). Therefore, the optimal voucher price is $P_{v 1}^{*}\left(N_{D}\right)=\left(1-\gamma_{e}\right)\left[A\left(N_{D}\right) V_{H}+\left(1-A\left(N_{D}\right)\right) V_{L}\right]$.

Using a similar argument, we can get the optimal voucher price under refund policies R2 and R3, i.e., $P_{v 2}^{*}$ and $P_{v 3}^{*}$, as follows: $P_{v 2}^{*}\left(N_{D}\right)=P_{v 3}^{*}\left(N_{D}\right)=A\left(N_{D}\right) V_{H}+\left(1-A\left(N_{D}\right)\right) V_{L}$.

Given the voucher price $P_{v i}^{*}(\mathrm{i}=1,2,3)$, DCs will buy the vouchers first. Then, observing $N_{D}$ vouchers have been sold (provided $Q>N_{D}$ ), UCs will update their expectations of having a valuation of $V_{H}$ to $A\left(N_{D}\right)$ and therefore accept the voucher price $P_{v i}^{*}$. As a result, they will buy the vouchers as well. Given that the merchant's top priority is to attract new customers (i.e., UCs), her possible capacity allocation decision $Q$ will be within the set $\mathscr{B}=\{0\} \cup\left\{N_{D}+\right.$ $\left.1, N_{D}+2, \ldots, C\right\}$. In other words, the merchant will either choose not to promote at all or to 
run the discount voucher promotion and make sure some UCs will get the vouchers.

Given $N_{D}$, if the merchant sets $Q \in\left\{N_{D}+1, N_{D}+2, \ldots, C\right\}$, then her expected profit under policy $\operatorname{RiSj}(\mathrm{i}=1,2,3, \mathrm{j}=1,2)$ can be expressed as follows:

$$
\begin{aligned}
\Pi_{i j}\left(Q \mid N_{D}\right)=\widetilde{P}_{i j}^{*}\left(N_{D}\right) Q+ & \widetilde{P}_{0} \sum_{l=0}^{N_{D}} \sum_{m=0}^{Q-N_{D}} b\left(l ; N_{D}, 1-\gamma\right) b\left(m ; Q-N_{D}, 1-\gamma\right)\left[\sum_{n=0}^{C-l-m} n b\left(n ; N_{H}-N_{D}, \xi\right)\right. \\
& +\sum_{n=C-l-m+1}^{N_{H}-N_{D}}(C-l-m) b\left(n ; N_{H}-N_{D}, \xi\right) \\
& \left.+\delta \sum_{k=0}^{j} b(k ; m, \alpha)\left(\sum_{n=0}^{C} n b\left(n ; N_{H}+k, \xi\right)+\sum_{n=C+1}^{N_{H}+k} C b\left(n ; N_{H}+k, \xi\right)\right)\right]
\end{aligned}
$$

where the effective voucher price $\widetilde{P}_{i j}^{*}\left(N_{D}\right)$ are given as follows:

$$
\begin{array}{ll}
\widetilde{P}_{11}^{*}\left(N_{D}\right)=\tau P_{v 1}^{*}\left(N_{D}\right)-s(1-\gamma) ; & \widetilde{P}_{12}^{*}\left(N_{D}\right)=\tau(1-\gamma) P_{v 1}^{*}\left(N_{D}\right)-s(1-\gamma) ; \\
\widetilde{P}_{21}^{*}\left(N_{D}\right)=(\tau-\gamma) P_{v 2}^{*}\left(N_{D}\right)-s(1-\gamma) ; & \widetilde{P}_{22}^{*}\left(N_{D}\right)=(\tau(1-\gamma)-\gamma) P_{v 2}^{*}\left(N_{D}\right)-s(1-\gamma) ; \\
\widetilde{P}_{31}^{*}\left(N_{D}\right)=\tau P_{v 3}^{*}\left(N_{D}\right)-s(1-\gamma) ; & \widetilde{P}_{32}^{*}\left(N_{D}\right)=\tau(1-\gamma) P_{v 3}^{*}\left(N_{D}\right)-s(1-\gamma) .
\end{array}
$$

If she chooses not to promote at all, then her expected profit can be expressed as follows:

$$
\Pi_{i j}\left(0 \mid N_{D}\right)=\widetilde{P}_{0}(1+\delta)\left(\sum_{n=0}^{C} n b\left(n ; N_{H}, \xi\right)+\sum_{n=C+1}^{N_{H}} C b\left(n ; N_{H}, \xi\right)\right)
$$

Denote $Q_{i j}^{*}\left(N_{D}\right)$ and $\Pi_{i j}^{*}\left(N_{D}\right)$ as the optimal capacity allocation decision and the optimal expected profit when the amount of DCs is $N_{D}$. Also, define function $\Delta_{i j}\left(N_{D}\right) \triangleq \widetilde{P}_{i j}^{*}\left(N_{D}\right)-\widetilde{P}_{i j}^{*}\left(N_{D}-1\right)$ as the marginal increment of the network effect due to the $N_{D}$ th DC.

Proposition 4 Under policy RiSj, if $Q_{i j}^{*}\left(N_{D}+1\right)>0$ and $\Delta_{i j}\left(N_{D}+1\right)>\bar{\Delta}$, then $\Pi_{i j}^{*}\left(N_{D}+1\right)>$ $\Pi_{i j}^{*}\left(N_{D}\right)$, i.e., the merchant is better off having more diluted customers, where

$$
\begin{aligned}
\bar{\Delta}=[ & \widetilde{P}_{0} \gamma \xi \sum_{l=0}^{N_{D}} \sum_{n=0}^{C-l-1} b\left(l ; N_{D}, 1-\gamma\right) b\left(n ; N_{H}-N_{D}-1, \xi\right) \\
& \left.+\widetilde{P}_{0}(1-\gamma) \xi \sum_{l=0}^{N_{D}} \sum_{n=0}^{C-l-2} b\left(l ; N_{D}, 1-\gamma\right) b\left(n ; N_{H}-N_{D}-1, \xi\right)+\widetilde{P}_{0} \delta \alpha \xi \sum_{n=0}^{C-1} b\left(n ; N_{H}, \xi\right)\right] N_{D}^{-1} .
\end{aligned}
$$

At first glance, customer dilution seems to be a bad thing for the merchant because the discount vouchers should have been sold to attract new customers instead of the existing customers. However, diluted customers also have two positive effects on the merchant's expected profit. 
First, the DCs may not think about coming to the merchant in the spot period if they do not have the voucher. Thus, the discount voucher plays a role in inducing consumption. Second, as many scholars (Jing and Xie, 2011; Nelson, 1970) have pointed out, there are information gaps between customers, particularly in the service industry. Thus, DCs will have a positive information externality that will help increase the UCs' valuation. The value of customer dilution depends on the relative value of the negative and positive effects. Proposition 4 shows the potential gains from the existence of DCs can possibly overweigh the corresponding losses. This result implies instead of specifically choosing not to advertise the discount voucher to her existing customers, the merchant may be better off informing some of her old customers about the upcoming discount voucher promotion campaign.

Shapiro and Varian (1999, pg.79) state "Promotional pricing is valuable only if it segments the market." This statement is based on the idea that promotion users usually have to bear some additional cost. For instance, "coupon users have to clip the coupon and remember to take it to the store" (Shapiro and Varian, 1999, pg.79). In other words, they emphasize the self-selection function of a promotion. However, in the current study, we find even though the merchant cannot perfectly segment the market (i.e., she cannot distinguish DCs from UCs in the discount voucher channel), she can still benefit from such promotion campaign. The main reason is the existence of the customer preference uncertainty. To realize "self" selection, a customer has to be certain about his valuation, which may not be known to the merchant. Then, the merchant will come up with certain mechanisms (e.g., promotion) to let the customer reveal his type. However, what if the customer does not know his valuation for sure? This means customer's willingness-to-pay can change during the purchasing and consumption process. Discount voucher mechanism offers the merchant two ways to influence the customer's willingness-to-pay: (a) it lowers the price to attract uninformed customers to experience the service and find their true valuation, and (b) it promotes the network effect among customers, which can influence UCs' expected valuation of the service. Hence, even though the merchant cannot segment the market, she can still benefit from the promotion campaign as long as there is customer preference uncertainty. 
It should be noted that the condition $\Delta_{i j}\left(N_{D}+1\right)>\bar{\Delta}$ is only dependent on the marginal increment of the network effect and is irrelevant to the absolute value of the effective voucher price. Thus, even though the effective voucher price may be very low, which implies the merchant is losing significant amounts of money from the diluted customers, the customer dilution effect may still benefit the merchant.

In addition, it is easy to check that $\forall(i, j) \neq(3,1), \Delta_{31}\left(N_{D}+1\right)>\Delta_{i j}\left(N_{D}+1\right)$. Then, according to Proposition 4, where the threshold $\bar{\Delta}$ is the same for all policies, we can see, given the same amount of DC (i.e., $N_{D}$ ), adding one more DC is more likely to be a good thing under policy R3S1 than under other five policies. In this sense, R3S1 is the most effective in utilizing the network effect among customers.

Corollary 2 The threshold $\bar{\Delta}$ is increasing in $C$ and $\delta$, and decreasing in $s$.

Larger $C$ and $\delta$ values indicate the merchant is more eager to increase her customer pool so that she can better utilize her large capacity and increase future profit. However, diluted customers will take some vouchers that are intended for potential new customers. Moreover, diluted customers will cost the merchant significant amount of money because they are expected to pay more. Thus, customer dilution behavior can be beneficial to a merchant with large $C$ and $\delta$ only when the network effect generated by DCs (i.e., $\left.\Delta_{i j}\left(N_{D}+1\right)\right)$ is sufficiently large.

As far as the merchant is concerned, selling a voucher to an IC will incur two types of loss: (1) the direct loss from selling to him at the discount price instead of at the original high price $P_{0}$ in the spot period, i.e., $\widetilde{P}_{0}-\widetilde{P}_{i j}^{*}\left(N_{D}\right)=P_{0}-P_{v i}^{*}\left(N_{D}\right)-s \gamma$, and (2) the future loss from losing a potential new customer in the future period, i.e., $P_{0}-s$. Both are decreasing in $s$. In other words, the cost of customer dilution for the merchant decreases with increasing $s$. As a result, Corollary 2 shows that the threshold $\bar{\Delta}$ is decreasing in $s$, which implies customer dilution is more likely to be a good thing for the merchants with higher variable cost. Thus, they should encourage their existing customers to participate in the discount voucher channel as their "sales agent" to help them attract new customers. 


\subsection{Simulation Study.}

In Section 5.1, we built our model based on the following two critical assumptions: (i) the merchant can expect $N_{D}$ rationally, and (ii) the model is static. In this section, we use a simulation study which relaxes these two assumptions to validate our main results in Section 5.1.

The basic setting of the example includes $C=70, N_{H}=100, P_{0}=10, s=0, \tau=1, V_{H}=$ $10, V_{L}=3, \alpha_{e}=0.1, \alpha=0.2, \xi=0.3, \gamma_{e}=0.2, \gamma=0.2, \delta=1$, and the implementation of the R1S1 policy ${ }^{15}$. In the discount voucher channel, suppose customers, each with the demand of one unit of capacity, arrive according to a Poisson process. Set $\Delta t$ very small such that at most one customer arrives within the time period. Without loss of generality, we set $\Delta t=1$. In total, the voucher selling period will last for $T=160$. Furthermore, within the time period $\Delta t$, the UC's arrival rate is assumed to be $\lambda_{U C}=0.5$ while the IC's arrival rate is denoted as $\lambda_{I C}$. The probability that an arriving IC is an ICH (or an ICL) is 50\%. Thus, the arrival rate of ICH (or ICL) is $0.5 \lambda_{I C}$. Following previous studies (e.g., Farrell and Saloner, 1986; Strauss, 2002), we use the following linear function to characterize the network effect: $A(n)=\alpha_{e}+k n$, where $k>0$ measures the magnitude of the network effect. Upon arrival, each UC will value his $A(n)$ based on the current sales $n$. If his expected payoff of buying the voucher (i.e., $\left.\left(1-\gamma_{e}\right)\left[A(n) V_{H}+(1-A(n)) V_{L}\right]-P_{v}\right)$ is negative, then the $\mathrm{UC}$ will wait in the discount voucher channel and constantly update his $A(n)$. Once his expected payoff turns out to be nonnegative, he will buy the voucher and leave the channel. The decision of the diluted ICs is relatively simple. Upon arrival, the diluted ICs will buy the voucher when the payoff (i.e., $\left(1-\gamma_{e}\right) V_{H}-P_{v}$ for the ICH and $\left(1-\gamma_{e}\right) V_{L}-P_{v}$ for the ICL) is nonnegative or leave otherwise.

We conducted 12 scenarios, i.e., $\lambda_{I C}=0.1,0.2,0.3,0.4$ and $k=8 / 700,5 / 700,2 / 700$. Two different models were used in each scenario:

- Dynamic and stochastic model (denoted as Model 1). This is the model described above. For each possible combination of $P_{v}$ and $Q$, we generated 20,000 cases and calculated the approximate corresponding expected profit by taking the average of the profit in each case.

\footnotetext{
${ }^{15}$ We obtained similar results with the other policies. Thus, for exposition simplicity, we omit the results.
} 
Figure 3: Results of the simulation study.

(a) $\mathrm{k}=8 / 700$

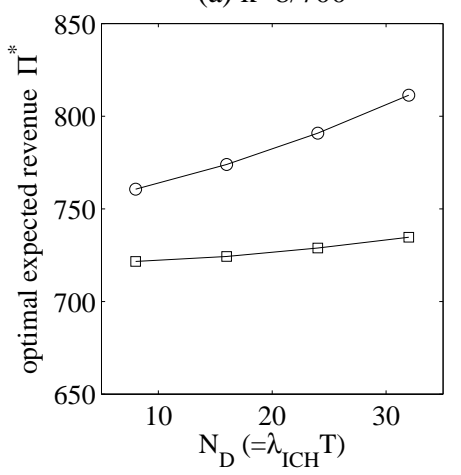

(b) $\mathrm{k}=5 / 700$

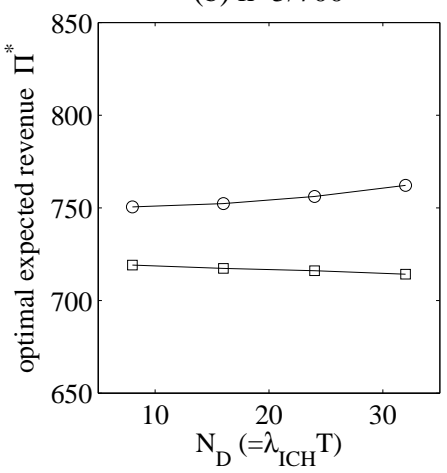

(c) $\mathrm{k}=2 / 700$

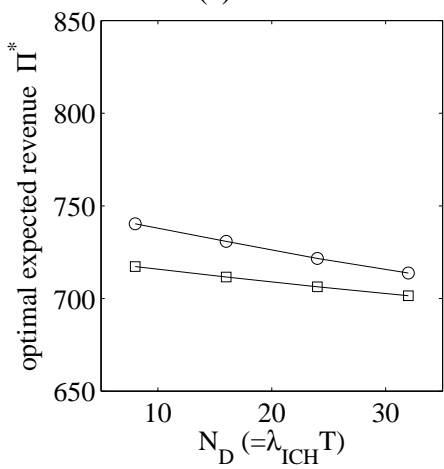

O-Model $2-\square-$ Model 1

Then, we searched for the optimal decision (i.e., $P_{v}^{*}$ and $Q^{*}$ ) and the optimal expected profit for each scenario.

- Static and deterministic model (denoted as Model 2), where $N_{D}=\lambda_{I C H} T$. This is the model discussed in Section 5.1, and thus, the optimal voucher price $P_{v}^{*}=(1-$ $\left.\gamma_{e}\right)\left[A\left(N_{D}\right) V_{H}+\left(1-A\left(N_{D}\right)\right) V_{L}\right]$. We obtained $Q^{*}$ by solving the optimization problem $\max _{Q \in \mathscr{B}} \Pi_{i j}\left(Q \mid N_{D}\right)$. Then, we calculated the corresponding optimal expected profit.

The results of the simulation study are given in Figure 3.

Proposition 4, which is based on the simple static and deterministic model (i.e., Model 2), points out that more diluted customers in the discount voucher channel may sometimes lead to an increase in merchant's optimal expected profit. As we can see in Figure 3, a similar phenomenon is obtained under certain circumstances (i.e., when $k=8 / 700$ ) in the dynamic and stochastic setting (i.e., Model 1). Furthermore, under the settings of both models, the merchant's optimal expected profit is more likely to increase in the (average) number of diluted customers $\left(\lambda_{I C H}\right.$ or $\left.N_{D}\right)$ as $k$ increases (i.e., the magnitude of network effect becomes stronger). Thus, a threshold $\hat{k}$ could exist such that $\forall k>\hat{k}$, the customer's dilution behavior and the merchant's optimal expected profit have a positive relationship. Admittedly, the threshold $\hat{k}$ can be different in the two models: Note when $k=5 / 700$, Model 1 generates a decreasing curve while Model 2 generates an increasing curve, which implies the $\hat{k}$ of Model 2 is smaller 
than that of Model 1. In general, the result that the merchant's optimal expected profit can sometimes (particularly when $k$ is large) increase as more informed customers dilute in the discount voucher channel, which is the main point of Proposition 4, is robust. Thus, even though our simple model proposed in Section 5.1 is based on strong assumptions, we find this kind of simplification captures the main characteristics of the actual settings.

\section{Conclusion and Future Research}

In this paper, we discussed the discount voucher, a mechanism widely used by merchants in the service industry nowadays owing to the success of online voucher vendors like Groupon and LivingSocial. Customers in this market have two types of valuation uncertainties, namely, preference uncertainty and consumption state uncertainty. Moreover, the merchant cares about not only the current operational performance, but also the long-term promotion effect. By taking a comprehensive perspective (i.e., considering revenue management and promotion effect at the same time), we found several new results that previous study fail to obtain:

i. Different from the traditional operations management viewpoints, we found no show of voucher buyers may not be a good thing for the merchant, especially for those large or start-up ones.

ii. Different from the existing marketing literature (e.g., Xie and Shugan (2001)) which claims offering refund is sometimes good for the merchant given voucher buyers have rational expectation about the probability of not being able to redeem the voucher, we found new evidence to show the negative effects of refund. Moreover, we found one best refund and revenue sharing policy (i.e., R3S1, not the Paypal model R3S2) in terms of maximizing social welfare, which may give some insights to the public policy.

iii. Different from the economics literature (e.g., Shapiro and Varian (1999)) which states promotional pricing is valuable only if it segments the market, we found customer dilution (i.e., imperfect market segmentation) may still benefit merchants due to the network effect. 
To our knowledge, there is little empirical work on the impacts of refund policy and customer behaviors (e.g., no-show and dilution) on the merchant's long-term revenue in the discount voucher market. We hope there will be more empirical studies on these issues to validate the predictions of our model in the future.

In this paper, to simplify the analysis, we used some restrictive assumptions. For instance, we assumed consumers are homogeneous when purchasing the vouchers and they only have two possible customer valuations, namely, $V_{H}$ and $V_{L}$. Although many papers on advance selling and reservations (e.g., Cil and Lariviere, 2013; Xie and Shugan, 2001) use a similar model, the case where UCs are heterogeneous in the voucher channel with valuation following a generous distribution is worth exploring. In addition, we simply treat the merchant's capacity as fixed at $C$. In some cases, the merchant's capacity might be flexible to some extent (e.g., the restaurant can open a "patio" to seat more customers). We think if we treat the capacity $C$ as the maximum capacity that the merchant can serve, then our analysis should remain the same. However, if providing extra capacity requires the merchant to pay more variable cost, then the analysis would be different. Specifically, the optimal capacity allocation decision $Q^{*}$ would change. Studying the effectiveness of the discount voucher mechanism in this situation would be an interesting topic for future research. Besides, we just considered the merchant as a monopoly. Future research can investigate the competitive setting where competing firms decide whether to sell digital vouchers. Similarly, the game between the voucher vendor and the merchant is also an interesting research topic. In this paper, we assumed the voucher vendors' market is competitive such that $\tau$ is an exogenous variable. For future research, we can let such variable be the voucher vendor's decision variable. Then, there will be a Stackelberg game where the voucher vendor first chooses the commission rate $1-\tau$ and then the merchant chooses the optimal voucher price $P_{v}$ and capacity allocation decision $Q$.

\section{Acknowledgement}

The authors would like to thank to the department editor, the senior editor, and three referees for their insightful comments and suggestions. This paper was supported by the National 
Natural Science Foundation of China (71232007).

\section{References}

Barr, A. 2011. Groupon doubles users, will drop controversial metric. Reuter (August 5).

Bils, M. 1989. Pricing in a customer market. The Quarterly Journal of Economics 104(4) 699-718.

Chen, Jian, Xilong Chen, Xiping Song. 2002. Bidder's strategy under group-buying auction on the internet. Systems, Man and Cybernetics, Part A: Systems and Humans, IEEE Transactions on 32(6) 680-690.

Chen, Jian, Xilong Chen, Xiping Song. 2007. Comparison of the group-buying auction and the fixed pricing mechanism. Decision Support Systems 43(2) 445-459.

Chen, Y., Q. Wang, J. Xie. 2011. Online social interactions: A natural experiment on word of mouth versus observational learning. Journal of marketing research 48(2) 238-254.

Cil, Eren B, Martin A Lariviere. 2013. Saving seats for strategic customers. Operations Research 61(6) 1321-1332.

Cooper, J. 2011. I consider groupon the single worst decision i've ever made as a business owner. Business Insider (March 24).

Dholakia, U.M. 2010. How effective are groupon promotions for businesses? Working paper, Rice University.

Dholakia, U.M. 2011. What makes groupon promotions profitable for businesses? Working paper, Rice University.

Dholakia, U.M. 2012. How businesses fare with daily deals as they gain experience: A multi-time period study of daily deal performance. Working paper, Rice University. 
Dholakia, U.M., G. Tsabar. 2011. A startup's experience with running a Groupon promotion. Working paper, Rice University.

Edelman, B.G., S Jaffe, S.D. Kominers. 2010. To groupon or not to groupon: The profiability of deep discounts. Working paper, Harvard Business School.

Edgar, D.A. 1997. Economic aspects. Ian Yeoman, Anthony Ingold, eds., Yield Management: strategies for the service industries. Cassell, London, 12-18.

Farrell, J., G. Saloner. 1986. Installed base and compatibility: Innovation, product preannouncements, and predation. The American Economic Review 76(5) 940-955.

Georgiadis, G., C.S. Tang. 2010. Optimal reservation deposit policies in the presence of rational customers and retail competition. Working paper, Univeristy of California, Los Angeles.

Hickins, M. 2011. Fee splits at groupon vary. Wall Street Journal (May 12).

Huang, J.H., Y.F. Chen. 2006. Herding in online product choice. Psychology and Marketing 23(5) 413-428.

Jing, X., J. Xie. 2011. Group-buying: A new mechanism for selling through social interactions. Management Science 57(8) 1354-1372.

Li, X., L.M. Hitt, Z.J. Zhang. 2011. Product reviews and competition in markets for repeat purchase products. Journal of Management Information Systems 27(4) 9-42.

Littlewood, K. 1972. Forecasting and control of passengers. 12th AGIFORS Symposium Proceedings. 95-117.

Mcdonald, D. 2012. The high value of discount prices. Wall Street Journal (June 22).

Nelson, P. 1970. Information and consumer behavior. The Journal of Political Economy 78(2) $311-329$.

Parker, G.G., M.W. Van Alstyne. 2005. Two-sided network effects: A theory of information product design. Management Science 51(10) 1494-1504. 
Roehert, K. 2010. A deal on a haircut? That's what friends are for. Wall Street Journal (March 24).

Shapiro, C., H.R. Varian. 1999. Information rules: a strategic guide to the network economy. Harvard Business Press.

Shugan, S.M. 1980. The cost of thinking. Journal of Consumer Research 7(2) 99-111.

Strauss, S. 2002. Three essays on marketing strategies in e-commerce and business-to-business service industries. Ph.D. dissertation. Yale School of Management, New Haven, CT.

$\mathrm{Su}$, X. 2009a. Consumer returns policies and supply chain performance. Manufacturing $\mathcal{E}$ Service Operations Management 11(4) 595-612.

$\mathrm{Su}, \mathrm{X} .2009 \mathrm{~b}$. A model of consumer inertia with applications to dynamic pricing. Production and Operations Management 18(4) 365-380.

Surowiecki, J. 2010. Groupon clipping. The New Yorker (Dec 20).

Veeraraghavan, S., L. Debo. 2009. Joining longer queues: Information externalities in queue choice. Manufacturing \& Service Operations Management 11(4) 543-562.

Xie, J., S.M. Shugan. 2001. Electronic tickets, smart cards, and online prepayments: When and how to advance sell. Marketing Science 20(3) 219-243. 